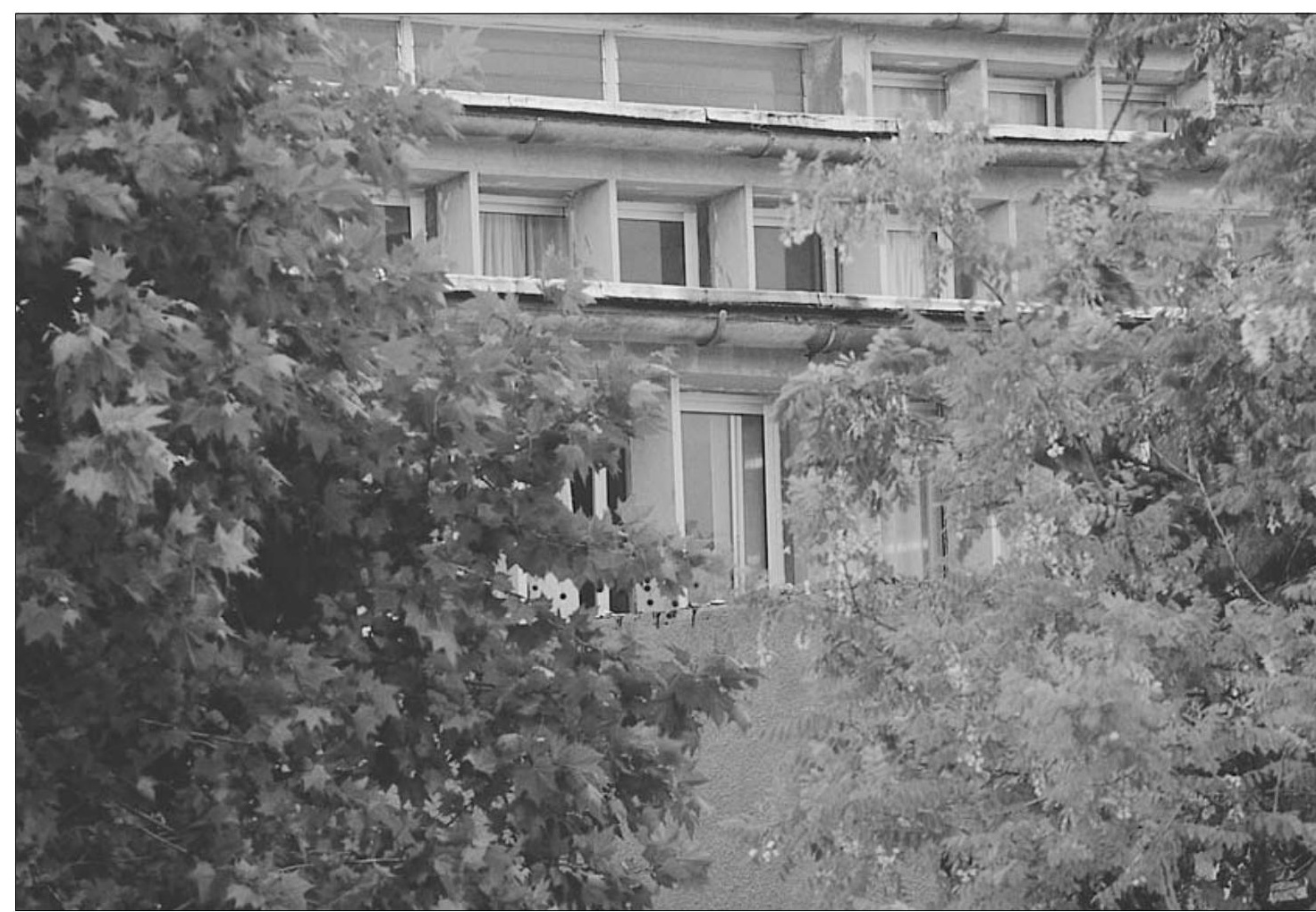

\title{
Arquitectura
}

\section{y Movimiento Moderno en Andalucía}

Victor Pérez Escolano

Arquitecto
Arquitectura del Movimiento Moderno. Una cuestión previa

E controversia. Su significación mítica en la mayoría de las historias de la arquitectura contemporánea publicadas entre los años treinta y los sesenta, desde Giedion a Benevolo, hizo que se generara un rechazo no sólo a la lectura unidireccional del fenómeno de la modernidad arquitectónica, sino en la propia utilización del término; baste recordar la resistencia de Manfredo Tafuri a hacerlo.

No obstante, la expresión "movimiento moderno" ha devenido en un uso comúnmente aceptado para designar al conjunto de las experiencias arquitectónicas de todo tipo y magnitud producidas voluntariamente, 
con mayor o menor tensión conceptual y figurativa, dentro del marco de la renovación antihistoricista producida a partir de las vanguardias radicales del siglo XX. Esta visión laxa del movimiento permite llevar a cabo una consideración universal y abierta de la producción "moderna" desarrollada en todo el orbe. Una fórmula de integración en la que, tanto el centro como la periferia, o más correctamente, los diversos centros y las distintas periferias en distintos planos y escalas de esa universalidad, toda obra adscribible a una "voluntad de modernidad", por circunstancial, ligera y banal que fuese, podría ser objeto de atención. Un planteamiento positivista que, suspendiendo en principio todo juicio, facilitaría las labores de prospección general, el inventario de una realidad y su relato más objetivo.

Con frecuencia se intercambian los conceptos de movimiento moderno, arquitectura racionalista o funcionalista y estilo internacional; todas ellas construcciones culturales creadas en condiciones muy determinadas, que no es del caso relatar. Tanto más se produce ese uso analógico de los términos cuanto más relajadamente se establece un discurso sobre la arquitectura surgida en los años veinte, especialmente en la Europa más desarrollada, y diseminada a continuación en sus planteamientos más superficiales por todo el mundo. Así, la arquitectura racionalista es voz que goza de especial fortuna para referir las innovaciones surgidas en los últimos años veinte y primeros trenta; baste recordar la exposición celebrada en Como en 1989 sobre L'Europa dei razionalisti. Pittura, scultura, architettura negli anni trenta, en cuyo catálogo, precisamente, Juan José Lahuerta, hablando de racionalismo y arquitectura en España, refería el problema a la cuestión de "estilo", identificado entonces como "construcciones blancas sin olvidar la influencia de las fotografias en blanco y negro-, volúmenes simples, prismáticos y cilíndricos, ventanas horizontales, escaleras exteriores y pasamanos de tubo...". Una formalización que bastaría para poner en crisis, según Lahuerta, incluso buena parte de la arquitectura española adjetivada como racionalista; cuanto más para encontrar ejemplos que busquen, netamente, convertirse simultáneamente en un medio para su propaganda. Ahí radicaría la reserva para la sola arquitectura del GATEPAC (Grupo de Artistas y Técnicos para el Progreso de la Arquitectura Contemporánea), especialmente en su formación catalana GATCPAC, promotora de la revista AC Documentos de Actividad Contemporánea, primacía ya defendida por Oriol Bohigas desde su libro Arquitectura Española de la Segunda República. Aún así, una historia "incompleta, sólo eso", ahogada por la Guerra Civil. Capítulo particular de la frustración, de la quiebra del horizonte civil del "proyecto moderno", sistema superior, descrito y reivindicado por Jürgen Habermas, en el que se explicarían las componentes transformadoras de las estructuras sociales, también por la contribución del movimiento moderno de la arquitectura del siglo $X X$.

Aceptar la sucesiva configuración de esferas excéntricas de las "devaluaciones periféricas" respecto de los paradigmas centrales de la modernidad arquitectónica, como modo de establecer la descripción de las realidades regionales de la modernidad arquitectónica.
Reunir las realizaciones producidas en una coyuntura de dimensión cronológica bastante, entre los años veinte y los sesenta, a fin de contar con los elementos de un relato suficientemente distinguible; y hacerlo con la laxitud necesaria que permita incluir aquellas variantes y modalidades, incluso maneras estilísticas. Así se configura la selección llevada a cabo por el DoCoMoMo lbérico, en la que figuran los veinte ejemplos andaluces reunidos en este número de $\mathrm{PH}$, y de ese modo, con mayor determinación, se prosigue en la extensión del trabajo hacia la formación de un Inventario Andaluz de la Arquitectura del Movimiento Moderno promovido por el Instituto Andaluz del Patrimonio Histórico,

\section{Limitaciones para la introducción del Movimiento Moderno en Andalucía}

Andalucía, como otras regiones meridionales europeas alejadas de la industrialización, de la formación de burguesías dinámicas y del establecimiento de atributos metropolitanos, ofrecía las condiciones menos apropiadas para la recepción de los fundamentos más estructurales del movimiento moderno. Por otro lado, las condiciones culturales de los años veinte en Andalucía tampoco eran propicias para un reflejo nítido del sistema figurativo racionalista. Baste pensar en la Exposición Iberoamericana de 1929, gestada durante dos décadas, quedó marcada por la intensificación de la arquitectura tradicional al terminar la primera década del siglo y se configuró como una de las manifestaciones españolas más amplias y poderosas del historicismo de raíz decimonónica.

En efecto, había resultado impresionante la respuesta de los jóvenes arquitectos de principios de siglo a las proclamas historicistas en que derivó la conservadora declinación de las crisis noventayochista. El historicismo se conjugó con las modalidades regionalistas más conspicuas, al punto de que una figura como Aníbal González, autor de los más importantes edificios de la Exposición Iberoamericana (las Plazas de América y de España), pudo devenir en el arquitecto andaluz mítico de su tiempo, e incluso de todo el siglo $X X$.

La prolongada, y en buena medida penosa, duración del proceso constructivo de la muestra iberoamericana, vino a marcar, desde la pujanza a la rigidez, el desarrollo del ambiente arquitectónico andaluz, especialmente en Sevilla. La arquitectura tradicional, en sus diversas versiones, historicista y regionalista, neocolonial e indigenista, se intensificó en los últimos años, especialmente desde 1925. Años que se corresponden, precisamente, con el impulso más decidido de la nueva arquitectura en Europa, y no sólo bajo los parámetros racionalistas emergentes, cuanto en otras variantes mas moderadas de innovación como pueda ser la arquitectura decó que encuentra en la Exposición Internacional de Artes Decorativas de París de 1925 su mayor plataforma de expansión.

Se hace necesario puntualizar que la intensidad y general predominio de la arquitectura tradicional en la sevillana Exposición Iberoamericana, tampoco estuvo aje- 
na del todo al eco de la renovación, impermeable a moderados ecos de la novedad. En primer lugar, hay que recordar que J. C. N. Forestier, que había diseñado la reconversión del Parque de María Luisa, llega a proponer en 1924 una ordenación del llamado sector sur de la Exposición cuyos dibujos nos muestran la hipótesis de un paisaje decó de gran interés. Una arquitectura decó que sólo se manifestaría netamente en el PabeIlón de Industrias Catalanas proyectado por J. Mestres Fosas. Junto a ese edificio, otros más modestos, igualmente desaparecidos: Maggi, de Fernando de la Cuadra y Jesús Guinea; Gal, de Vicente Sáenz; El Eclipse, de Julio Jiménez; o la marquesina del de Información que introduce José Granados en el de Información proyectado con Vicente Traver, amén de algún proyecto no realizado, por ejemplo por Luis Fernández-Palacios Palazuelos; todos ellos acompañaron al de Mestres Fosas en esa presencia minoritaria que ha estudiado Alberto Villar Movellán, como toda la arquitectura del primer tercio de siglo. Decir también que una lectura cuidadosa de los edificios tradicionalistas de la Iberoamericana permitiría extraer ciertos valores de modernidad en proyectos especialmente creativos, como pueda ser el Pabellón de Chile (arquitecto Juan Martínez).

La dificultad que encuentra para su modernización la arquitectura andaluza se refleja en otros aspectos, por ejemplo los vinculados a la innovación técnica, que podría decirse permanecen ajenos a esa atonía regional, pues se rigen por circunstancias de orden general. Me refiero a la realización de obras de ingeniería civil, a veces con participación de algún arquitecto, las cuales, no obstante, son reducidas, como reducido es el progreso de las infraestructuras en nuestra región en el primer tercio de siglo. Son los casos de los puentes y viaductos, las obras hidráulicas, y algunos otras aplicaciones de los nuevos materiales y procedimientos constructivos.

Entre los numerosos proyectos promovidos aquí y allá en el territorio nacional por el destacado ingeniero de caminos José Eugenio Ribera, figuran el acueducto de la garganta del Chorro (1904-07), en Málaga, el dique seco y el acueducto de Tempul, en Cádiz, con la colaboración del joven Eduardo Torroja; colaboración que persiste en la última obra de Ribera, el puente de San Telmo de Sevilla (concurso 1920, inauguración 1931).

Entre las obras de naturaleza hidráulica hay que recordar las proyectadas por los ingenieros Carlos Mendoza y Alfonso del Aguila, y que cuentan con la colaboración del arquitecto Casto Fernández Shaw, figura destacadísima, pero peculiar y no exenta de contradicciones, en la búsqueda de la condición vanguardista de la arquitectura española de los años veinte. Cuatro saltos vinculados a la cuenca del Guadalquivir, los de El Carpio (1922, medalla de oro en la Exposición de Artes Decorativas de París de 1925), Encinarejo y Alcalá del Rio (1929-31), con Mendoza, y con Alfonso del Aguila el del Jándula (1924-32), en la Lancha/Andujar (Jaén), el más notable de todos ellos.

Añadir las aplicaciones de las nuevas técnicas de hormigón armado a obras industriales, militares o de transporte. En las de Sevilla cumple un papel muy destacado Luis Rank, un arquitecto y empresario alemán que desde 191 I se instala en España al ser llamada la empresa familiar por la Compañía Catalana de Gas y Electricidad. Desde ese año participa en la realización del complejo fabril sevillano, demolido en buena parte en estos últimos años, y cuyo proyecto arquitectónico realiza Anibal González. Junto con Rank participa el ingeniero, asimismo alemán, Víctor Schmitt, e incluso se traen obreros especializados desde Munich. La colaboración con Aníbal González se extenderá a la central térmica de la Compañía Sevillana de Electricidad. Años más tarde la empresa de Luis Rank construirá otras obras, como la cochera de tranvías en Triana (1928-3I, J. L. Sáez y J. Redondo), y especialmente la Base Aérea de Tablada (1922-23), bajo la dirección técnica del ingeniero militar Antonio Rodríguez Martín. Por su parte, los tinglados portuarios (1925-28) son proyecto del ingeniero José L. de Casso Romero. Añadir, al hilo de lo anterior, los proyectos no ejecutados para el naciente aeropuerto civil de Sevilla, en origen pensado como cabecera de la línea de dirigibles

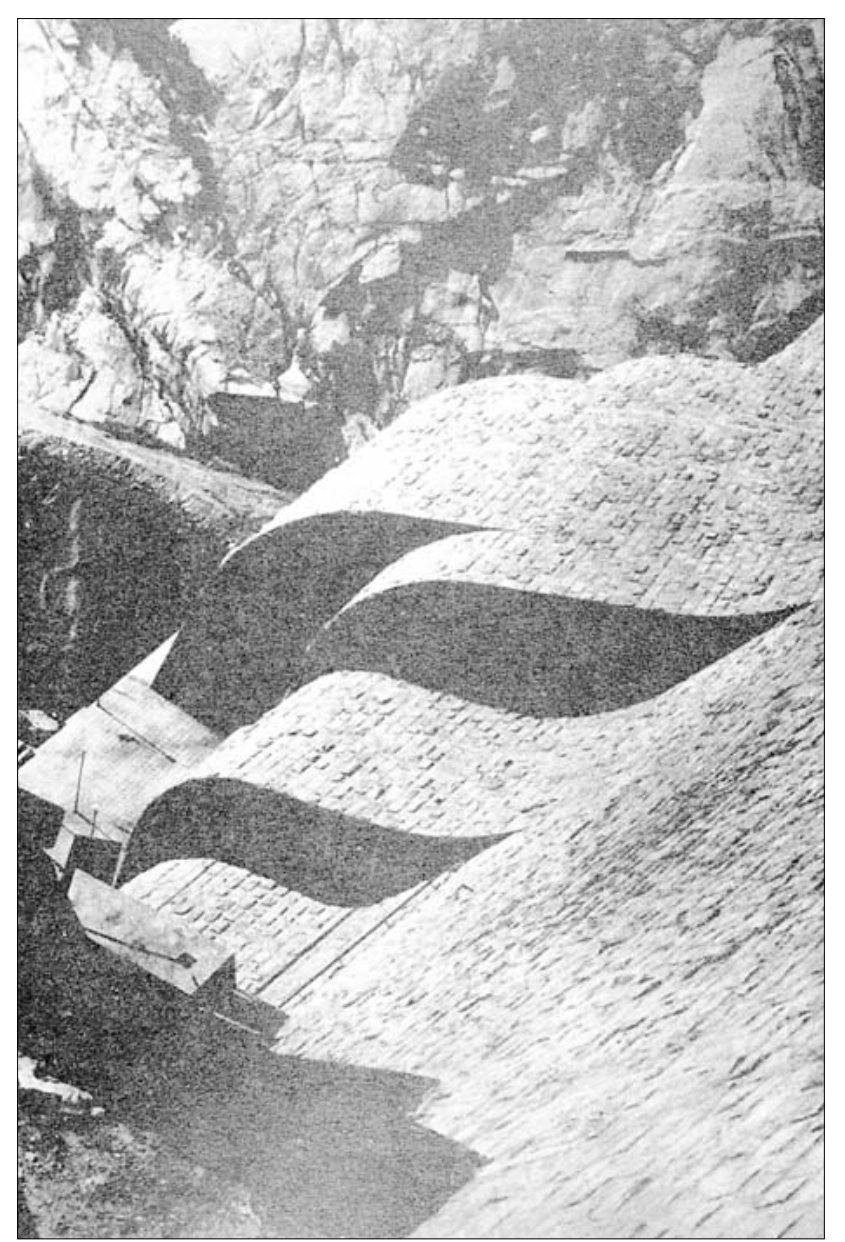

I. Casto Fernández Shaw (arq.) y Alfonso del Águila (ing.)

Europa-América, para los cuales se llegaron a proponer algunas soluciones ambiciosas como el cobertizo (1934) de superficie de 32.256 m2 y altura de 58 metros, proyectado por Alfonso Peña Boeuf.

La relación entre ingeniería y arquitectura moderna, en la que el hormigón armado cumple el papel protagonista, tendrá su expresión definitiva en Andalucía de la mano de Eduardo Torroja. Repasando la rela-
Salto de Jándula, en La Lancha, Jaén. 1924-1932 
ción completa de los proyectos redactados por el gran ingeniero de caminos se observan tres docenas entre obras de urbanización y saneamiento, puentes, viaductos y acueductos, obras hidráulicas y portuarias, y diversas estructuras de edificación. Las primeras en colaboración con Ribera, como ya se dijo, enseguida solo o en colaboración con arquitectos. Entre sus más importantes trabajos, citado junto a las famosas marquesinas del Hipódromo de la Zarzuela (con Arniches y Domínguez) o el Frontón Recoletos (con S. Zuazo), está la colaboración con Manuel Sánchez Arcas en el Mercado de Algeciras (1933-35), el más claro alarde estructural de su tiempo en un edificio urbano andaluz.

No obstante, se hace necesario referir aquí que el concierto entre diseño estructural y forma arquitectónica en un edificio público de esa naturaleza, cuenta con un ejemplo de notable importancia histórica, el mercado de abastos de la Puerta de la Carne en Sevilla, por tratarse de un proyecto propuesto a finales de 1926 por el joven arquitecto Gabriel Lupiáñez Gely, figura central de la reciente tesis doctoral realizada por José María Jiménez Ramón, autor de un artículo acerca de la catalogación de la arquitectura racionalista sevillana en este mismo número de PH. Boletín del IAPH.

\section{Modernidad y Arquitectura. Algunos referentes esenciales andaluces}

La tesis de Jiménez Ramón, una vez publicada, pondrá de manifiesto la amplitud del eco del moviniento moderno en Sevilla, y no sólo la personalidad de Lupiáñez, hasta ahora conocida y valorada pero no con la justeza y precisión que ya es posible. Obras como el citado mercado de la Puerta de la Carne, o el Instituto Anatómico Forense, entre otras muchas, en las que la cola-

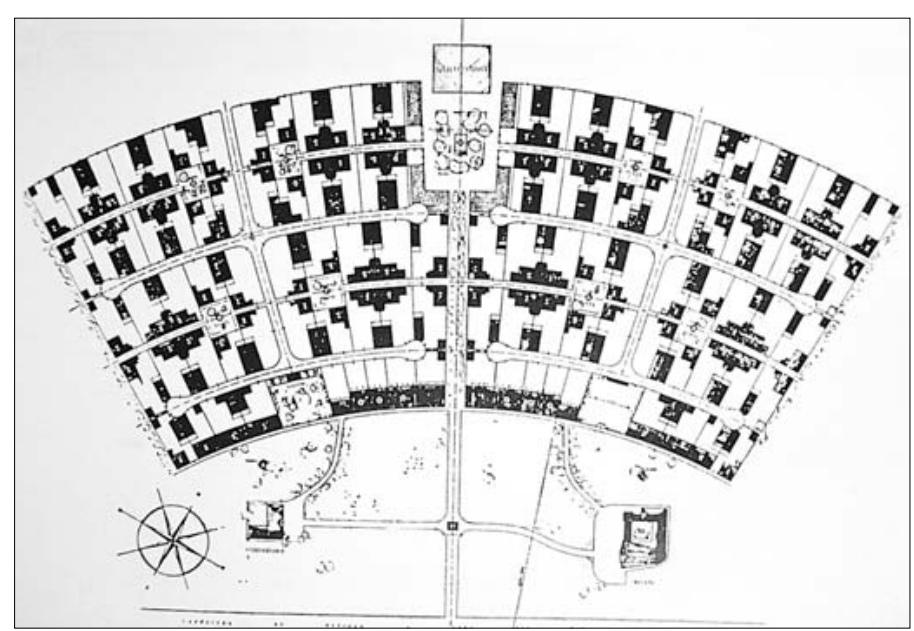

2. Alejandro de la Sota. Poblado de Colonización de Esquivel, Sevilla. 1952-53-56-63 boración con Rafael Arévalo Carrasco, destacan de manera especial en una pugna en la que también tiene un papel protagonista José Galnares Sagastizábal, y en menor grado José Granados de la Vega, Antonio Delgado Roig y Luis Carrera Díez, estos en colaboraciones con el veterano regionalista Juan Talavera y Heredia, o Joaquín Díaz Langa, entre otros.
No obstante, el interés de Lupiáñez reside en su intensidad modernizadora, en su decidida voluntad racionalista, una disposición intelectual que abarca muy diversas manifestaciones disciplinares y alcanza, insólito ejercicio en Andalucía, con su proposición de "Ciudad Funcional", inserta como encarte en el número I de 1935 de la revista Hojas de Poesía, de la que Abelardo Linares hizo edición facsímil. La inspiración internacional, tanto de Le Corbusier como de Richard Neutra, a la que no es ajena su subscripción a AC, revista barcelonesa del GATEPAC, coloca a su autor en un tono superior a sus colegas andaluces.

Pero el referente urbanístico, vital para medir el grado de vitalidad de la cultura moderna, carece de ejemplos verdaderamente destacados en nuestra región. Así, por ejemplo, Sevilla arrastra una precaria vicisitud en lo referente a un planeamiento operativo. Por añadidura, la requisitoria estatal que conduce al concurso de 1930 tiene un desenlace fallido y de muy escasa participación, si bien la propuesta del equipo del sevillano Pedro Sánchez Núñez nos resulta hoy de mayor interés que la de Fernando García Mercadal.

El emergente marco de la economía urbana ya había buscado ocasiones para tratar de introducirse en la ciudad andaluza. Baste recordar los planes de iniciativa privada de la sociedad Los Remedios para el ensanche de Triana, para los que Cristobal Mañas contó con la colaboración del eminente arquitecto y urbanista Secundino Zuazo. Trazados de notable envergadura orientados a desarrollar un substancial sector urbano que el transcurso de los años vino a configurarlo con cualidades urbanas muy inferiores a las inicialmente previstas. Hacer ciudad mediante una masiva programación de viviendas, se establecía como auténtica proyección del modelo de ensanche deciomonónico sobre nuevos parámetros de la técnica urbanística.

De igual modo que la incorporación del Parque de María Luisa al disfrute de los sevillanos se correspondía con un modelo cívico extendido por todo el mundo occidental. Un modelo que tendrá su reflejo en distintas ciudades andaluzas, como el proyecto de parque para Granada de Jean Graef (1929), estudiado por Angel Isac.

Un marco territorial en el que cabe encontrar otras frustaciones, sólo más tarde satisfechas sin duda en la estela de los precedentes. Me refiero al concurso de anteproyectos para poblados promovido en 1932 por el Ministerio de Agricultura, Industria y Comercio, recién creado, al amparo de la nueva Ley de Obras de Puesta en Riego. Un precedente republicano, en el que participan numerosos jóvenes arquitectos e ingenieros de toda España, de lo que luego el franquismo llevará a cabo bajo el impulso del Instituto Nacional de Colonización, con realizaciones, dispersas por distintas provincias andaluzas, tan destacadas como Esquivel (Alejandro de la Sota), La Vereda, Cerralba o Miraelrío (José Luis Fernández del Amo), o El Priorato (Antonio Fernández Alba).

La materialización arquitectónica en periodo republicano de un proyecto de modernización social se pro- 
duce en el campo de las construcciones escolares, de las que Marcelino Domingo llegó a promover 7.000 en todo el territorio español, elevando la moral del magisterio y creando en paralelo una línea de bibliotecas populares. Aunque su puesta en servicio venga a coincidir con el triunfo del levantamiento militar de 1936, valgan los ejemplos sevillanos: los Colegios Nacionales en Arroyo, La Barzola, Triana y Ciudad Jardín, proyectos municpales elaborados por L. Carrera Díez junto a Talavera a partir de 1934. Referencias que cabría extender a realizaciones en otras provincias, como el Colegio de Huérfanos de Ferroviarios de Torremolinos (1935), de Francisco Alonso Martos, y no sólo en los años republicanos, pues ya se inicia una renovación de la arquitectura escolar en la época de la Dictadura de Primo de Rivera, como por ejemplo la Escuela Nacional de Niños de Villafranca de Córdoba (1927) del arquitecto José Joaquín González Edo.

Otros ámbitos propios de la modernidad tuvieron en la nueva arquitectura el fundamento de su configuración; baste recordar los locales del espectáculo del siglo por excelencia, el cinematógrafo. La construcción de teatros y cines se intensifica desde mediados de los años veinte, $y$, al igual que sucede en Madrid, a su escala podemos ver en Andalucía, gracias al trabajo de Seviya/Gabinete de Proyectos, la evolución desde formulaciones historicistas hasta plenamente modernas, pasando por ejemplos de transición, como pueda ser el Teatro Villamarta de Jerez de la Frontera (1926-28) obra de Teodoro de Anasagasti, o el Cine Góngora de Córdoba (1929-31) de Luis Gutiérrez Soto. Hoy se conservan buenos ejemplos, como el Cine Rábida de Huelva (1931-33), del propio Gutierrez Soto, o los de de Antonio Sánchez Esteve, tanto en Cádiz (Cine Municipal, 1930-35, y el más tardío Teatro Andalucía, 1947-49) como en Antequera (Cine Torcal, 1933-34); otros notables, sin embargo, y por desgracia, han desaparecido, como dos importantes del propio Sánchez Esteve, el Cine Gades en Cádiz (1933) y el magnífico Málaga Cinema (1934-35), sin olvidar el Actualidades de Málaga, de González Edo.

\section{La diseminación andaluza de la arquitectura moderna. Arquitectos y obras}

Los edificios modernos de los años treinta en Andalucía son, en buena medida, expresión de la fortuna que un nuevo lenguaje encuentra entre los arquitectos más jóvenes. Son escasos los profesionales que adoptan un posicionamiento profesional plenamente comprometido con el significado ideológico de tal expresión formal. E igualmente muy pocas son las obras anteriores a 1930 que no deriven de las alusiones deco o formen parte de un proceso técnico, fuera del tono cultural clave en las mejores producciones europeas de esos años. Esa excepción podría estar representada en los arquitectos ya citados, Casto Fernández Shaw y Gabriel Lupiáñez Gely, uno de fuera y otro andaluz, que, como dijimos, si responden a una voluntad netamente innovadora.

Una transición en la que lo de fuera y lo de dentro se conjuga en una vicisitud en ocasiones ambigua. Ejem-

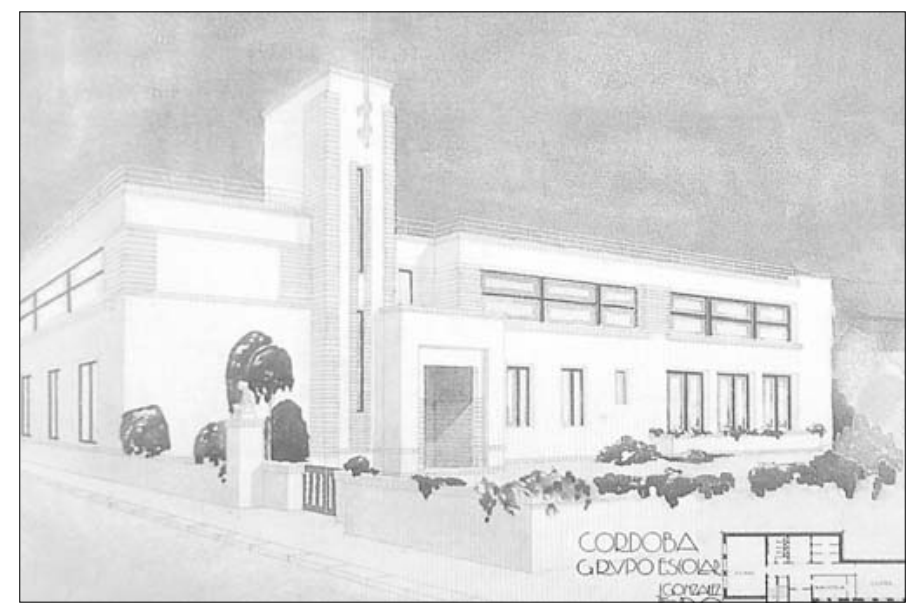

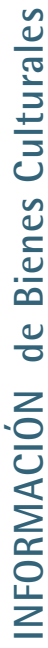

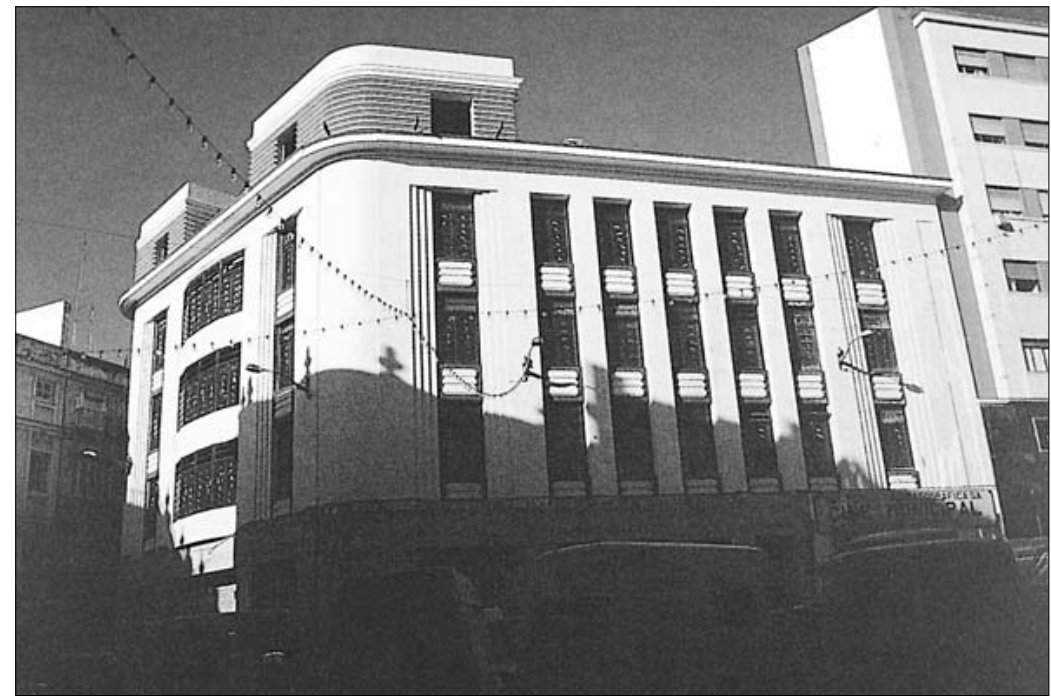

3. José L. Gonzáles Edo.

plar es el caso de una de las obras más atractivas de Andalucía: el carmen de la Fundación Rodríguez Acosta de Granada (19|4-28), cuya autoría sigue siendo difícil de discernir del todo entre la acción de Teodoro Anasagasti, substancial, de José Felipe Giménez Lacal, cierta, de Modesto Cendoya, circunstancial, y del propio pintor José María Rodríguez Acosta, definitiva. Escuela Nacional de Niños de Villafranca de Córdoba. 1927

4. Antonio Sánchez esteve. Cine municipal, Cádiz. 1930-35

5. Teodoro Anasagasti, José F. Giménez y M. Cendoya. Carmen de la Fundación Rodríguez Acosta, Granada. 1914-28

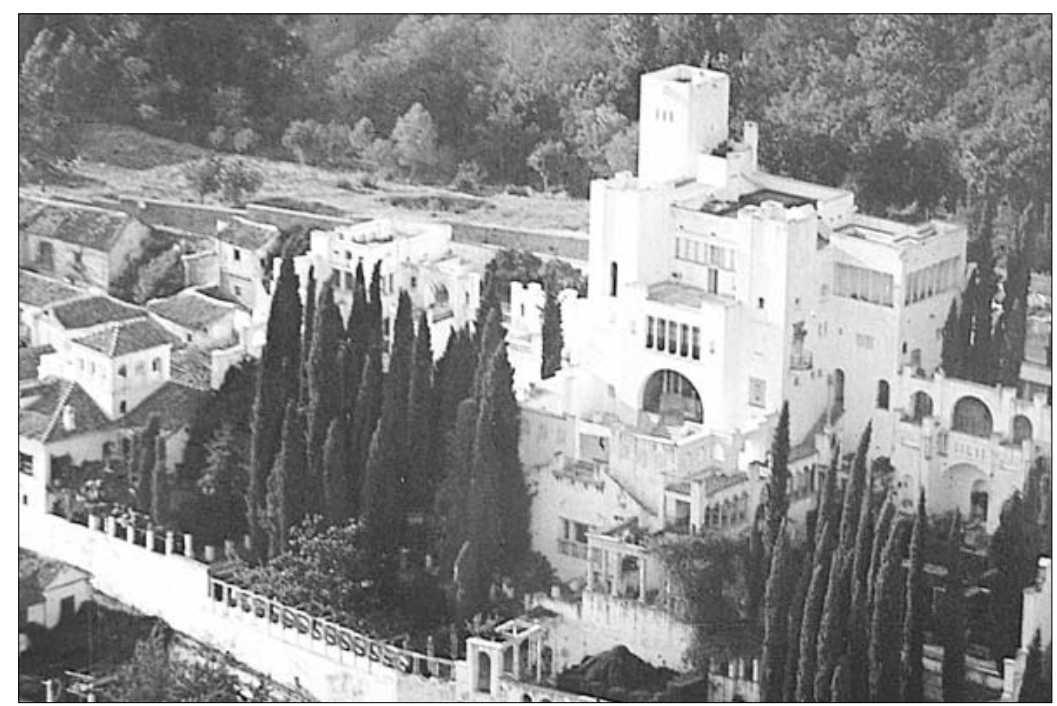



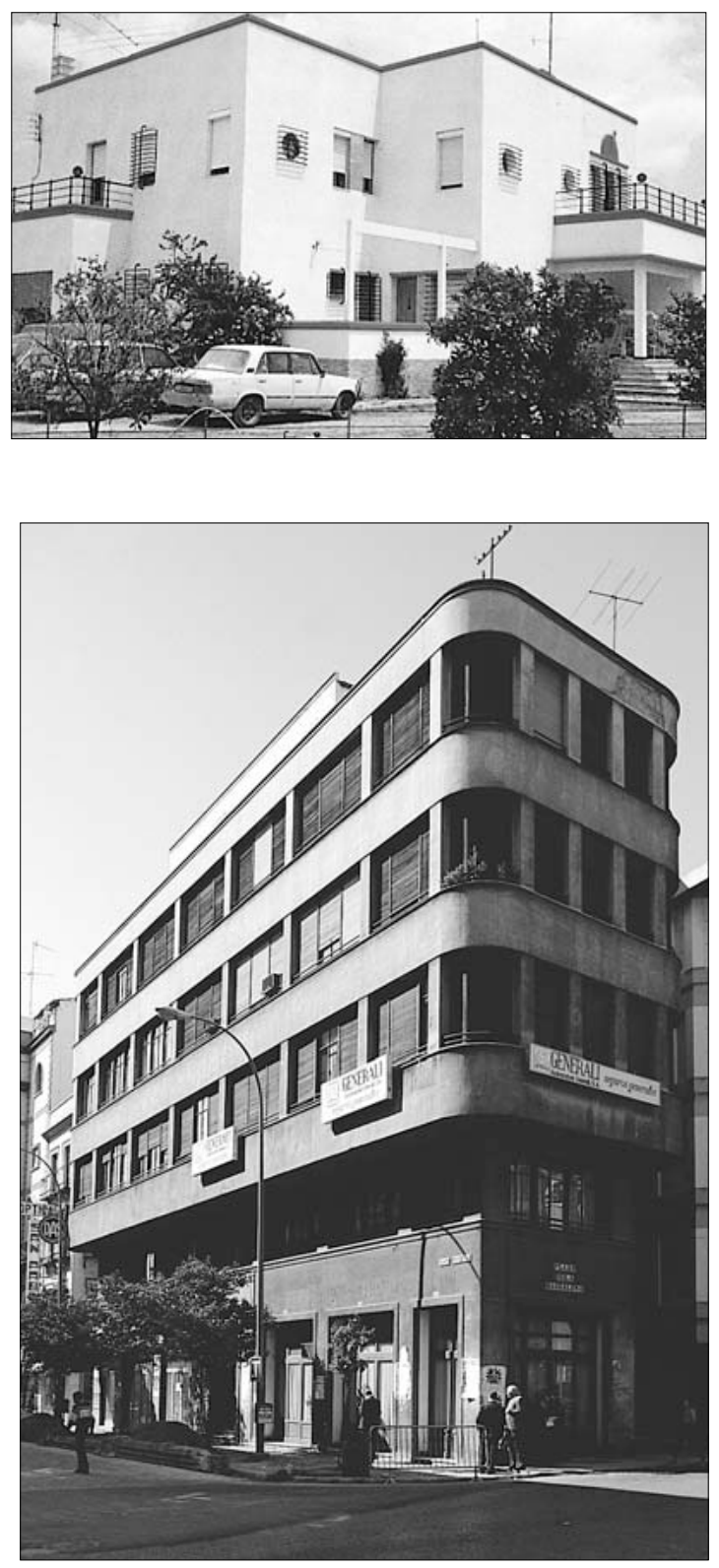

6. José M. Pérez Carasa.

Chalé "Plus Ultra",

en Gibraleón, Huelva. 1933

7. Rafael Arévalo. Edificio de viviendas ("Cabo Persianas"). en Sevilla. 1938

8. Juan Talavera y José Galnares. HYTASA. 1937-44

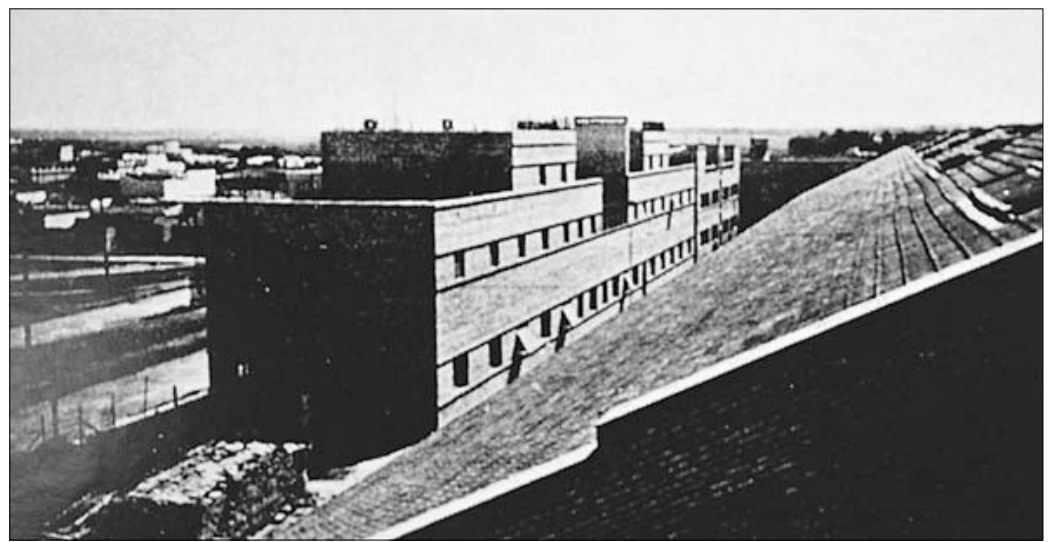

No obstante, es la casa Duclós en Sevilla (1929), de José Luis Sert, la obra que mejor representa la paradoja que ante el gusto imperante opera el racionalismo. En pleno fulgor de la Exposición Iberoamericana, Sert regala al doctor Duclós y su mujer, que recién casados vienen a instalarse a Sevilla, su opera prima, un trabajo que durante años permanecerá ignorado, y aún después de reconocido por el propio Sert no aparecerá ni siquiera reseñado en las monografias dedicadas al arquitecto catalán.

Así, pues, Sert se suma a la nómina de arquitectos no andaluces que dejan su huella en este proceso de innovación cultural. La mayoría, desde Zuazo a Anasagasti, pasando por Mercadal, Fernandez Shaw, Gutiérrez Soto..., son profesionales de Madrid; como es en Madrid donde la mayoría de los jóvenes andaluces desarrollan sus estudios de Arquitectura, siendo excepción (Galnares, por ejemplo) los que cursan en Barcelona. Los libros, las revistas, pero también los viajes serán fuente de inquietudes e inspiraciones; y así, entre los arquitectos andaluces, o que establecen su actividad en el territorio andaluz, guardarán de sus viajes especiales recuerdos, como los de Edo o Prieto-Moreno de Alemania.

Junto a Lupiáñez, tanto José González Edo (las citadas escuelas de Villafranca de Córdoba, 1927), afincado en Malaga, como el jerezano Fernando de la Cuadra (su propuesta en el concurso para Albergues de Automovilistas de 1929), se inician pronto en el racionalismo. Pero en el tránsito a la década de los treinta se multiplica la nómina de los arquitectos aplicados en esa dirección: Langle en Almería, Prieto Moreno en Granada, Pérez Carasa en Huelva, Sánchez Esteve en Cádiz y Málaga, y Galnares o Delgado Roig en Sevilla, todos ellos con obra en los años de la Segunda República. Un panorama al que Eduardo Mosquera y María Teresa Pérez Cano han dedicado estudios importantes.

Obras de distinta magnitud, desde los chalets (el Plus UItra en Gibraleón, de Pérez Carasa, 1933; o en el Paseo Marítimo en Almería, de Langle, 1932) a los edificios de vivienda colectiva (en calle Feria con Relator en Sevilla de Lupiáñez y Arévalo, 1935-37, el Lastrucci en la misma ciudad de Talavera y Delgado Roig, o el Desfile del Amor en el malagueño paseo de Reding, de González Edo, 1935), o los refugios de paz y de guerra (el de Sierra Nevada de Prieto Moreno, 1933-35, o los de defensa de bombardeos en Almería de Langle, 1937).

\section{Supervivencia y reactivación del Movimiento Moderno en el franquismo}

El prolongado drama de la Guerra Civil de 1936 a 1939 divide el territorio andaluz en dos partes, tras la inmediata caida en manos rebeldes del triángulo Sevilla-Cádiz-Huelva. Por consiguiente, la limitada actividad constructora de esos años aciagos tendrá en la arquitectura moderna una de sus paradojas. Sabemos que, salvo en los proyectos de carácter representativo, en los que el régimen franquista se decantará por la grandilocuencia autoritaria prestada por el historicismo, tal como operan las Dictaduras mussoliniana, hitleriana y stalinista, la actvidad cotidiana de los arquitectos de uno y otro lado no impedirá un cierto grado de supervivencia de un racionalismo débil. Paradoja que no deja de tener sus incidentes, como las presiones en contra del edificio conocido como Cabo Persianas (1938) en el centro de Sevilla, obra de Rafael Arévalo.

En Sevilla, las primeras viviendas de iniciativa pública en el Sector Sur (Antonio de la Vega y Jerónimo Junquera, 1937), en Vista Florida (Luis de Sala, 1937-39), Barrio León (Ayxalá Terrats, 1937-38) o La Barzola (Fonseca), forman parte de realismo pragmático en la aplicación de los recursos tipológicos, y también en buena medida formales, de la "tradición de lo nuevo".

Y de la vivienda a otras manifestaciones nada desdeñables. Mientras Fernández Shaw (lonja de pescado de Barbate, 1940) rememora su actividad andaluza, Gutiérrez Soto (mercado de mayoristas de Málaga, 1938-43) hace lo propio trasvistiendo desprejuiciadamente su racionalismo "republicano" en "franquista" mediante la adición del escudo del nuevo Estado. Entre los andaluces, Galnares, mantiene su pulso en proyectos urbanos (calle Rodríguez Jurado, 1938-4I), cuando inicia las obras del ambicioso establecimiento industrial de Hytasa (193744), mientras que, siempre en la misma ciudad, el joven Rodrigo Medina Benjumea inicia su actividad profesional 
con la estación de autobuses y viviendas municipales (1938). En Cádiz, Sánchez Esteve levanta la magnífica pieza del edificio de la Transmediterránea (1938), mientras que Langle prolongará, sin ningún reparo, su vis racionalista en Almería en las obras de la Ciudad Jardín (1942-47), o en la Estación de Autobuses (1952).

En el tránsito de los años cuarenta a los cincuenta, podría decirse que la supervivencia de la moderna disciplina se dota de nuevas energías de la mano de la nueva generación de posguerra, teniendo lugar una reactivación que es bien conocida en el panorama general de España, por la aparición de figuras como Sota u Oíza, en Madrid, o Coderch y Sostres en Barcelona. Un dinamismo generacional que, a su nivel, es perfectamente identificable en Andalucía, de la mano de arquitectos sevillanos como los hermanos Medina Benjumea, o Luis Recaséns (conjunto de viviendas de Los Diez Mandamientos, 1958-64); Fernando Cavestany en Cádiz (ambulatorio Hermanos Laulhé de San Fernando, 1954); Alejandro Herrero en Huelva (estación de servicio, 1955); o Rafael de la Hoz y José María García de Paredes, en Córdoba y Granada, autores de una pieza reveladora de un elocuente equilibrio institucional: la cordobesa sede de la Cámara de Comercio e Industria, cuyos interiores integran diseños propios con la aportación del escultor Jorge Oteiza en el mostrador de atención al público. Sólo de la Hoz, antes de desarrollar una copiosa y plural actividad, elaborará algunas piezas de excelente factura, como es el chalet Canals (1956), en la carretera de las Ermitas de Córdoba.

No obstante, si hubiese que elegir un tipo edilicio en el que se dirime el difícil equilibrio entre representación e innovación, deberíamos ir a los ejemplos de las Universidades Laborales, verdaderos simulaciones de la pretendida "revolución social" del falangismo. Pero lo que en Gijón Luis Moya proyecta, por lo demás magistralmente, en términos de un monumentalismo contundente, en Andalucía las Laborales de Córdoba (M. de los Santos, D. Sánchez-Puig, F. Robles y F. Cavestany, 1952-56) y de Sevilla (F. y R. Medina Benjumez, A. Toro y L. Gómez Estern, 1953) consiguen resultados excelentes mediante planteamientos exclusivamente operados desde los recursos proyectuales y técnicos del movimiento moderno.

Un movimiento moderno que penetra en la década de los sesenta con el proceso desarrollista de la economía española, cuya bonanza favorece la realización de operaciones más intensivas y cuyos resultados habrán de adolecer de quebrantos urbanos y territoriales, así como de reducciones culturales evidentes. En los inicios de la conversión de la Costa del Sol en un inmenso soporte de la más poderosa industria turística, podemos ver piezas arquitectónicas interesantes, como la Casa Lange (1959) proyectada por el wrightiano Robert Mosher con José Relaño, o la Ciudad Sindical de Vacaciones en Marbella, de Aymerich y Cadarso.

Una década, los sesenta, no exenta, sin embargo, de obras relevantes que inciden en valores ya consagrados o apuntan nuevas interpretaciones. Treinta años después de su protagonismo juvenil, Eduardo Torroja y Fernando de la Cuadra pueden establecer una nueva y magnífica colaboración en las bodegas Tío Pepe (1960-63) de Jérez de la Frontera. García de Paredes podrá, por su parte, llevar

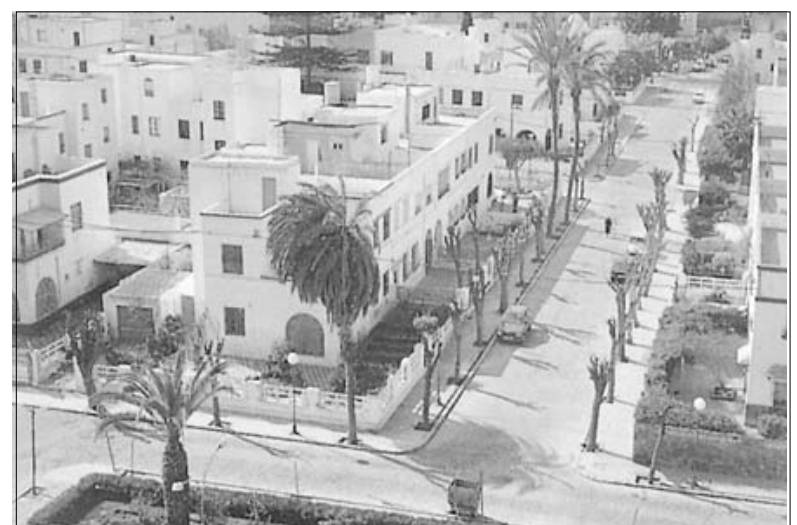

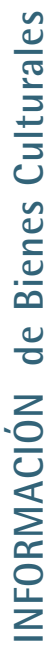

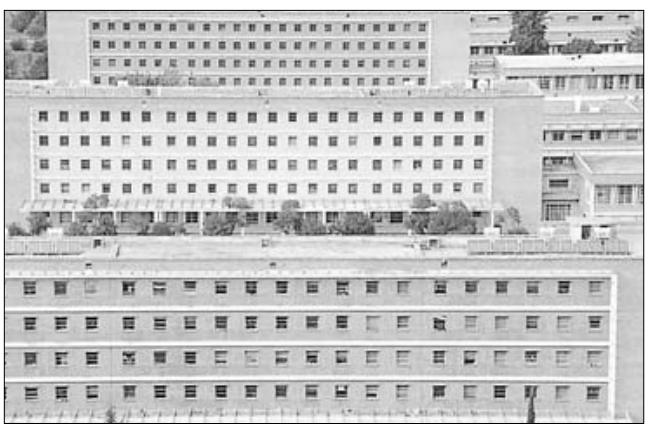

9. Guillermo Langle. Viviendas en la Ciudad Jardín de Almería. 1942-47

10. F. y R. Medina Benjumea, A. Toro y L. Gómez Estern.

Universidad Laboral de Sevilla. 1953

a cabo una de sus mejores obras, la malagueña iglesia de Stella Maris (1961-66), junto a otros ejercicios funcionales también de gran austeridad constructiva (Centro de Enseñanza Media Juan XXIII de Granada, 1964).

Veteranos y más jóvenes participaron, pues, entre los veinte y los sesenta, en un notable capítulo arquitectónico dentro de nuestro siglo $X X$ que, al concluir, nos reclama una ardua labor de análisis, inventario, interpretación, evaluación, difusión, protección, conservación y rentabilización, a fin de integrar el patrimonio de nuestro tiempo en la copiosa herencia de un pasado cultural cuya vitalidad no decae.

Por ello, hay que saludar el compromiso adquirido por el Instituto Andaluz del Patrimonio Histórico con la compleja vertiente contemporánea de nuestra arquitectura. Su apoyo a las iniciativas del DoCoMoMo lbérico se inscribe un objetivo permanente en pro de la salvaguarda de los más relevantes manifestaciones del Movimiento Moderno en Andalucía, como parte de la cultura contemporánea, del que este número de $\mathrm{PH}$ da testimonio.

II. M. Aymerich y A. Cadarso. Ciudad Sindical de Vacaciones en Marbella, Málaga. 1956-1962

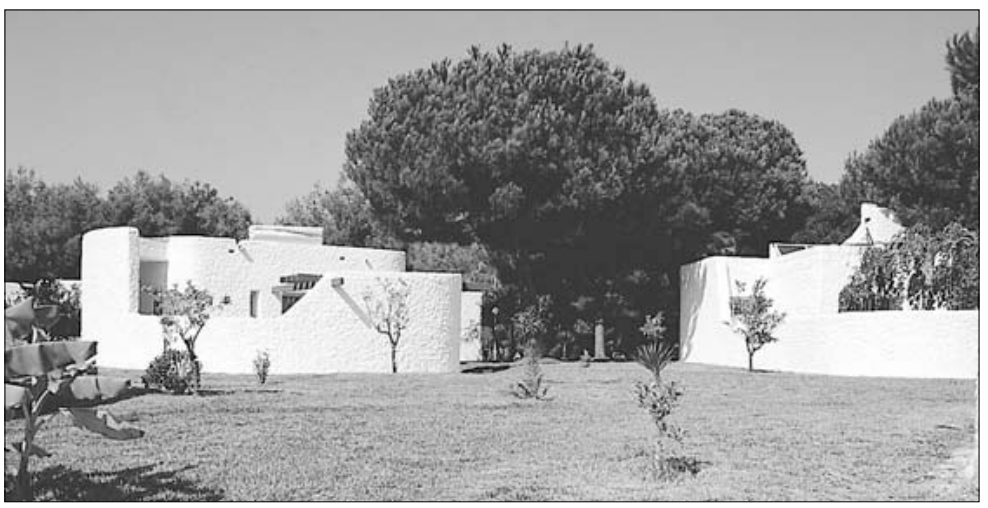

